\title{
Formação continuada de professores em educação ambiental crítica: uma análise das perspectivas e limites de um projeto de extensão
}

\section{Continuing teacher education in critical environmental education: an analysis of the prospects and limits of an extension project}

\section{Formación continua de docentes en educación ambiental crítica: un análisis de las perspectivas y límites de un proyecto de extensión}

\author{
Leonardo Kaplan ${ }^{1}$ \\ Kelly Azevedo Vidal ${ }^{2}$ \\ Larissa do Nascimento Dawidman ${ }^{3}$ \\ Larissa Hagler de Santana ${ }^{4}$
}

\begin{abstract}
Resumo
O objetivo desta pesquisa foi analisar, no contexto de um projeto de extensão em educação ambiental (EA) com professores de escolas públicas, suas concepções sobre a integração entre universidade e escola, suas compreensões sobre as macrotendências no campo da EA, bem como refletir sobre as perspectivas e limites do projeto. O referencial teórico-metodológico contempla o materialismo histórico-dialético com aportes da Pedagogia Histórico-Crítica e da vertente marxista da EA Crítica. Os dados foram coletados por meio de relatos orais, entrevistas semiestruturadas e observações durante as oficinas do projeto de extensão. Verificou-se que alguns professores tiveram dificuldade em compreender as três macrotendências como perspectivas teóricopráticas distintas, abraçando um ecletismo. Percebeu-se que a precarização do trabalho docente traz limitações às práticas pedagógicas, mas as ações extensionistas fortaleceram a autonomia docente para desenvolver atividades com base na EA Critica.
\end{abstract}

Palavras-chave: Educação ambiental crítica. Extensão universitária. Formação continuada de professores.

\begin{abstract}
The goal of this research was to analyze, in the context of an extension project in environmental education (EE) with public school teachers, their conceptions about the integration between university and school, their understandings about the macrotrends in the field of EE, as well as reflect on the perspectives and limits of the project. The theoretical-methodological reference is the historical-dialectical materialism with contributions of Historical-Critical Pedagogy and the marxist strand of Critical EE. Data were collected through oral reports, semistructured interviews and observations during the extension project workshops. It was verified that some teachers found it difficult to understand the three macrotrends as distinct theoretical-practical perspectives, embracing eclecticism. It was perceived that the precariousness of the teaching work brings limitations to the pedagogical practices, but the extensionist actions strengthened the teaching autonomy to develop activities based on the Critical EE.
\end{abstract}

Keywords: Critical Environmental Education. University extension project. Continued teacher training.

\section{Resumen}

\footnotetext{
${ }^{1}$ Professor Adjunto da Faculdade de Educação da Universidade do Estado do Rio de Janeiro (EDU/UERJ), Departamento de Estudos Aplicados ao Ensino (DEAE). leonardokaplan@gmail.com

${ }^{2}$ Doutaranda do Programa de Pós-Graduação em Educação da Universidade Federal do Rio de Janeiro (PPGE/UFRJ). kellyvidalufrj@yahoo.com.br

${ }^{3}$ Graduada em Ciências Biológicas pela Universidade do Estado do Rio de Janeiro (IBRAG/UERJ). larissadawidman@gmail.com

${ }^{4}$ Graduanda em Pedagogia pela Universidade do Estado do Rio de Janeiro (EDU/UERJ). larissahagler@hotmail.com
} 
El objetivo de esta investigación fue analizar, en el contexto de un proyecto de extensión en educación ambiental (EA) con maestros de escuelas públicas, sus concepciones sobre la integración entre la universidad y la escuela, su comprensión sobre las macro-tendencias en el campo de EA, así como reflexionar sobre las perspectivas y los límites del proyecto. El marco teórico-metodológico es el materialismo histórico-dialéctico con contribuciones de la pedagogía histórico-crítica y del aspecto marxista de EA Critica. Los datos fueron recolectados través de informes orales, entrevistas semiestructuradas y observaciones durante los talleres del proyecto de extensión. Se descubrió que algunos maestros encontraron dificultades en entender las tres macro-tendencias en sus distintas perspectivas teórico-prácticas, abrazando una especie de eclectismo. Se observo que la precariedad del trabajo docente trae limitaciones a las prácticas pedagógicas, pero las acciones de extensión fortalecieron la autonomía docente para desarrollar actividades basadas en EA Crítica.

Palabras clave: Educación Ambiental Crítica. Extensión Universitaria. Formación continua del profesorado.

\section{Introdução}

O presente trabalho tem como foco a formação continuada de professores na perspectiva da Educação Ambiental (EA) Crítica, visando compreender os impactos da entrada de um projeto de extensão universitária em educação ambiental, na perspectiva crítica, junto ao corpo docente de uma escola municipal do Rio de Janeiro. Nesse sentido, buscamos analisar a parceria entre universidade e a escola, através da percepção dos professores quanto ao projeto, assim como determinar caminhos para implementá-lo em uma instituição da educação básica. Tevese como objetivos compreender as concepções dos docentes da escola acerca das macrotendências presentes no campo da EA, ao final do processo de formação continuada, e investigar como esses sujeitos pensam a relação entre universidade e escola, além de analisar perspectivas e limites do trabalho docente no interior da escola junto às ações extensionistas.

$\mathrm{O}$ artigo está dividido da seguinte forma. Iniciamos, apresentando o projeto de extensão que foi alvo da presente pesquisa. Em seguida, tratamos do debate acerca das concepções sobre extensão universitária, evidenciando nosso posicionamento em defesa de uma perspectiva extensionista de intercâmbio de conhecimentos e produções entre a universidade e as instituições (sobretudo públicas) e grupos sociais, especialmente, aqueles mais vulneráveis social, econômica, política e ambientalmente. Em um terceiro momento, abordamos as relações entre os campos da educação ambiental (EA) e da formação de professores, no sentido de refletir acerca dos limites e das possibilidades da inserção da EA, em sua vertente crítica, nos contextos escolares. Incluímos, nesse debate, outros aspectos que consideramos estruturantes para a entrada e permanência da EA nas escolas, tais como condições de trabalho dos docentes, gestão escolar e currículo, bem como materiais didáticos alinhados à perspectiva crítica de EA. Posteriormente, caracterizamos a Pedagogia Histórico-Crítica, abordagem teóricometodológica que orientou o projeto, seguida da discussão metodológica e descrição das etapas e atividades do mesmo. Por fim, apresentamos e analisamos os resultados, e concluímos com algumas considerações finais.

O projeto Educação Ambiental para professores de escolas públicas: perspectivas teóricas e práticas teve início em 2016 e, atualmente, reúne professores e licenciandos dos cursos de Pedagogia e de Ciências Biológicas da UERJ. Em 2018, o projeto iniciou suas ações em uma nova escola, localizada no centro do município do Rio de Janeiro. Esta atende a estudantes do $6^{\circ}$ ao $9^{\circ}$ ano do ensino fundamental e turmas do $1^{\circ}$ ao $5^{\circ}$ ano do Programa de Educação de Jovens e Adultos (PEJA), nos turnos da manhã, tarde e noite, totalizando 736 alunos. O projeto tem fornecido subsídios teórico-metodológicos para professores das redes públicas da educação básica, visando a produção de materiais e atividades, adotando os 
referenciais da Pedagogia Histórico-Crítica e da Educação Ambiental Crítica na vertente marxista, de modo a possibilitar um fortalecimento da autonomia docente.

No escopo da função social das universidades públicas, há três dimensões indissociáveis: a pesquisa, o ensino e a extensão. A extensão torna-se uma importante instância de mediação entre os conhecimentos científico-tecnológicos, filosóficos e artístico-culturais produzidos pela comunidade universitária e as demandas presentes na sociedade (SEVERINO, 2016), como fecundo intercâmbio entre conhecimentos com vistas ao fortalecimento dos grupos sociais (especialmente, os alinhados às funções sociais das universidades públicas e/ou em situação de maior vulnerabilidade socioeconômica e ambiental) aos quais se destinam tais ações.

Kochhann (2017) defende que a extensão universitária é um dos componentes curriculares responsáveis pela formação de professores, no Brasil. Apoiada em Reis (1989 apud KOCHHANN, 2017, p. 276) a autora identifica duas grandes linhas de concepção sobre a extensão, sendo uma de caráter "eventista-inorgânica como prestação de serviços ou atividades esporádicas desvinculadas do contexto e do processo de aprendizagem" e uma "outra processual-orgânica, permanente e imersa no processo formativo e produção de conhecimento, em parceria com a sociedade de forma oxigenante e transformadora". Ao analisarem as concepções em disputa no processo de institucionalização da extensão universitária no Brasil, Tauchen, Monteiro e Viero (2012, p. 15) vislumbraram que a primeira grande tendência, ao longo da história, foi a extensão como uma via de "mão única", uma "forma de retorno à sociedade daquilo que essa investe na universidade, como uma forma de corrigir a ausência de comunicação e de intervenção da universidade nas problemáticas da sociedade". Daí denota o caráter assistencialista e de prestação de serviços, conforme mencionado por Kochhann (2017). Por sua vez, a segunda tendência apontada por Tauchen, Monteiro e Viero (2012), inspirada na concepção freireana, compreende a extensão como uma via de "mão dupla" entre a universidade e a sociedade, concepção esta que foi expressa pelo Fórum de Pró-Reitores de Extensão das Universidades Públicas Brasileiras (FORPROEX), a partir de 1987.

Nesse sentido, o projeto de extensão objeto desta pesquisa configura suas ações de forma a buscar fortalecer a autonomia dos professores da escola parceira, elaborando atividades escolares em colaboração entre a equipe do projeto e os docentes, fomentando o papel emancipatório da extensão na integração universidade-escola. Logo, buscamos nos contrapor às demais iniciativas de entrada de agentes externos para desenvolver ações de educação ambiental nas escolas, por vezes lideradas por ONGs e empresas, que oferecem materiais e atividades prontas, cabendo ao professor apenas reproduzi-las. Sob o argumento de facilitar a vida do professor, essa estratégia busca reforçar o controle ideológico desses agentes sobre o trabalho docente, dificultando sua atuação crítica em sala de aula. Entendemos isto como problemático, pensando que essa ação considera o professor como mero reprodutor, rejeitando sua capacidade intelectual de formular criticamente, na direção de uma formação humana emancipatória (MAIA; TEIXEIRA, 2015).

Conforme Maia, Teixeira e Agudo (2015), a EA, geralmente, é trabalhada nas escolas nas disciplinas de Ciências, Biologia e Geografia, pois o currículo está estruturado de modo a responsabilizar os docentes dessas áreas do conhecimento como os principais agentes capazes de trabalhar questões ambientais em sala de aula, talvez, por conta da própria formação inicial desses profissionais. Entretanto, compreendemos que a discussão ambiental tange diversas áreas de conhecimento. Assim, o projeto desenvolve a possibilidade de uma inserção transversal da educação ambiental no currículo escolar.

A formação continuada de professores é um campo em disputa. Segundo Macedo (2017), há duas grandes tendências: a primeira, hegemônica e encampada por organismos internacionais (Pnuma, Unesco, Banco Mundial etc.), de caráter legitimador da precarização das condições de trabalho do docente e da alienação do trabalhador docente; a segunda, em uma 
perspectiva emancipatória, isto é, para além das exigências do capital, conferindo profundidade e solidez aos conhecimentos, pautando-se pela apropriação crítica do conhecimento produzido pelas ciências sociais, no sentido ontológico, e orientando-se pelo princípio da totalidade, dominando seja os conhecimentos do campo educacional quanto os conteúdos historicamente produzidos pela humanidade e, por fim, articulando-se a atividade educativa com as lutas desenvolvidas pela classe trabalhadora (MACEDO, 2017, p. 271-277). Portanto, o caráter da maioria das políticas de formação de professores, no Brasil, é um aspecto central que tem dificultado a entrada de uma abordagem crítica de EA nas escolas públicas, já que esse modelo de formação, "na prática, valoriza o treinamento ou capacitação de habilidades e competências que [...] resultam na formação técnica que valoriza a prática sem a teoria, sem a reflexão teórica e crítica do trabalho didático (MAIA; TEIXEIRA, 2015, p. 299).

Outro agravante é a desarticulação do trabalho coletivo dos docentes das escolas para trabalhar a questão ambiental, por conta tanto das condições de trabalho, que não permitem a elaboração de um projeto político pedagógico comum, conforme apontam Macedo e Mello (2017), quanto pela carência de discussões sobre EA na formação inicial dos docentes das variadas licenciaturas, o que incorre em uma dificuldade dos mesmos em trabalhar a EA nas escolas, sobretudo em sua vertente crítica.

Nessa escola municipal, no ano de 2018, o projeto de extensão teve, como uma de suas linhas, o desenvolvimento de atividades na perspectiva da Educação Ambiental Crítica em parceria com docentes de diferentes disciplinas (Artes Cênicas, Ciências, Geografia, História, Língua Inglesa e Língua Portuguesa nas turmas regulares do $6^{\circ}$ ao $9^{\circ}$ ano e em uma turma do Projeto Aceleração, que reúne alunos que teriam idade para estar no $8^{\circ}$ ou $9^{\circ}$ ano. As atividades foram desenvolvidas a partir de temáticas de interesse dos professores das turmas: lixo eletrônico (Ciências, $9^{\circ}$ ano), lixo e classe social (Língua Inglesa, Aceleração), água e seca (Artes Cênicas, $6^{\circ}$ ano), impactos socioambientais das obras da ditadura militar (História, $9^{\circ}$ ano), água (Geografia, $9^{\circ}$ ano) e discussão sobre o discurso da sustentabilidade ambiental (Língua Portuguesa, $7^{\circ}$ ano).

Segundo evidências empíricas, é possível apontar para uma escassez de materiais didáticos e atividades que contemplem a perspectiva crítica da EA dentro das escolas. Figueira et al (2015, p. 480), por exemplo, constataram que a alimentação "tem sido abordada em livros didáticos com ênfase no valor nutricional dos alimentos e nas doenças causadas por sua carência ou excesso, mas a grave questão dos aditivos químicos e dos agrotóxicos é, ainda, superficial e limitada nestes materiais".

Portanto, tanto as pesquisas sobre a EA nas escolas, como observado por autores desse campo (COSTA; LIMA, 2015; RODRIGUES et al., 2019), quanto as observações empíricas dos projetos e ações de educação ambiental nas escolas, em sua maioria, partem de uma abordagem conservadora. Layrargues e Lima (2014) identificam três macrotendências da EA no Brasil: EA Conservacionista, EA Pragmática e EA Crítica. As duas primeiras situam-se em um campo conservador das relações sociais, resultam em ações de caráter individualista e comportamentalista, à medida que responsabilizam um ser humano genérico como causador e vítima da crise ambiental, desprezando o papel do modo de produção capitalista no estabelecimento de relações sociais de exploração e de degradação do ambiente. Contrária a essa perspectiva, a EA Crítica, quando referenciada no materialismo histórico-dialético (MARX, 2008), busca a compreensão das problemáticas ambientais na sociedade capitalista, considerando a divisão de classes e as desigualdades sociais. É denominada, também, de EA Transformadora ou Emancipatória (LOUREIRO, 2003) dado seu caráter crítico-transformador das relações sociais capitalistas.

Conforme a pesquisa do MEC/INEP, intitulada $O$ que fazem as escolas que dizem que fazem educação ambiental? (BRASIL, 2007.), três aspectos são estruturantes para assegurar a inserção da EA nas escolas: a formação docente (formação inicial e continuada de professores), 
o currículo (diretrizes, arranjo e conteúdo) e a gestão escolar (reorganização da carga horária docente) (LIMA, 2007; LOUREIRO; COSSÍO, 2007 apud LAMOSA; LOUREIRO, 2011, p. 284).

Em seu estudo, Lamosa (2010) constatou que, nas escolas municipais de Teresópolis, RJ, não havia políticas de produção de materiais didáticos e de formação continuada de professores por parte da Secretaria Municipal de Educação, mesmo o MEC afirmando que são dois aspectos centrais para que a educação ambiental se estruture nas escolas. Isto abriu espaço para a entrada de empresas e ONGs que desenvolveram projetos de educação ambiental para as escolas públicas, promovendo, desde a formação continuada de professores, até a produção de materiais tendo em vista as concepções e objetivos das próprias empresas.

Nesse sentido, estão os efeitos das parcerias público-privadas nas escolas públicas: a entrada de empresas e ONG's nas escolas públicas preveem, quase sempre, cursos de capacitação de professores e elaboração de materiais didáticos que apenas reforçam a perspectiva ideológica mercantil e conservadora (LAMOSA, 2010). Assim, o centro de nossos esforços tem sido pensar a formação continuada de professores para possibilitar o desenvolvimento de uma abordagem crítica da EA nas escolas públicas, de modo a permitir o aprofundamento teórico-prático destes e fortalecer a autonomia docente. Defendemos uma formação docente que permita o fortalecimento da autonomia do trabalho docente, na perspectiva da desalienação do trabalho, isto é, um trabalho que possa superar seja a separação imposta pelas relações sociais capitalistas entre o trabalhador e os produtos que este produziu, a separação entre os trabalhadores no processo de produção, o estranhamento do trabalhador em relação a si mesmo e à própria natureza humana.

Com vistas a atuar nessa perspectiva educativa-formativa, consideramos os processos inspirados na abordagem da Pedagogia Histórico-Crítica (PHC) em sua relação com a EA Crítica, pois:

[...] se a educação é mediadora na atividade humana, articulando teoria e prática, a educação ambiental é mediadora da apropriação pelos sujeitos, das qualidades e capacidades necessárias à ação transformadora responsável diante do ambiente em que vivem. Podemos dizer que a gênese do processo educativo ambiental é um movimento de fazer-se plenamente humano pela apropriação/transmissão crítica e transformadora da totalidade histórica e concreta da vida dos homens no ambiente (TOZONI-REIS, 2007, p. 218).

Formulada, inicialmente, por Dermeval Saviani (2008) e colaboradores, a Pedagogia Histórico-Crítica (PHC) entende que:

\begin{abstract}
A pedagogia revolucionária é crítica. E por ser crítica, sabe-se condicionada. Longe de entender a educação como determinante principal das transformações sociais, reconhece ser ela elemento secundário e determinado. Entretanto, longe de pensar, como o faz a concepção crítico-reprodutivista que a educação é determinada unidirecionalmente pela estrutura social dissolvendo-se a sua especificidade, entende que a educação se relaciona dialeticamente com a sociedade. Nesse sentido, ainda que elemento determinado, não deixa de influenciar o elemento determinante. Ainda que secundário, nem por isso deixa de ser instrumento importante e por vezes decisivo no processo de transformação da sociedade (SAVIANI, 2008, p. 52).
\end{abstract}

Nesse sentido, a escola, embora determinada pelas relações sociais capitalistas, é uma instituição educativa central em nossa sociedade que, por conter em seu interior contradições provenientes de uma sociedade marcada pelos conflitos e desigualdades de classes, não pode ser desprezada em seu potencial de transformação da sociedade, por estar integrada à luta de classes. Assim, a extensão universitária, em nosso entendimento, contribui para a integração da comunidade acadêmica com a comunidade escolar, permitindo, por um lado, a formação inicial 
de licenciados e, por outro, a formação continuada dos professores, constituindo-se em uma troca recíproca entre ambas instituições.

\section{Metodologia}

O projeto tem como base teórico-metodológica o materialismo histórico-dialético com contribuições da Pedagogia Histórico-Crítica (PHC) (SAVIANI, 2008) e da Educação Ambiental Crítica (LOUREIRO, 2003), fundamentos que auxiliam a construir o processo de formação continuada com os professores da escola. A dinâmica da formação continuada ocorreu através de quatro oficinas, que aconteceram em dois dias de semestres diferentes, nos turnos da manhã e da tarde, no Centro de Estudos Integral (CEI) com o corpo docente da escola. Para isso, utilizamos como ferramenta data show e slides. As oficinas ocorreram, em cada turno, com um grupo de cerca de dez professores de todas as disciplinas, com a duração de 50 minutos. Até 2018, o CEI acontecia na rede municipal do Rio de Janeiro uma vez por bimestre, assegurando um dia para os docentes se reunirem, discutirem questões referentes à escola e, sobretudo, para sua formação continuada. As duas primeiras oficinas tiveram como intuito apresentar o projeto (seus objetivos, público-alvo, dinâmica de realização, exemplos de atividades) e a EA Crítica aos professores, e junto a isso, identificar os interessados e estabelecer um primeiro contato. A equipe esclareceu que o projeto não é pontual e a intenção é possibilitar meios para que os professores deem continuidade às ações, de maneira autônoma. As duas oficinas posteriores retomaram, resumidamente, os conteúdos das anteriores, pois se tratava de um grupo composto por alguns professores diferentes, e apresentaram o método da Pedagogia Histórico-Crítica (SAVIANI, 2008) para construir, junto com os professores, atividades de EA crítica para serem desenvolvidas em sala de aula. Nesse sentido, buscamos indicar que as atividades de EA não são restritas às disciplinas de Geografia, Ciências e Biologia, como usualmente são desenvolvidas (MAIA; TEIXEIRA; AGUDO, 2015). Durante a etapa das oficinas, registramos os conteúdos através de gravação de áudios.

Ao longo do ano, a equipe do projeto se reuniu semanalmente com os professores, nos horários dedicados ao planejamento de cada um, e desenvolveu, junto a eles, atividades que contemplassem os conteúdos que já buscavam trabalhar nas aulas ou que tivessem interesse em abordar com as turmas. A perspectiva foi a do trabalho colaborativo entre a equipe do projeto e os professores da escola, ou seja, em alguns casos os temas e a própria ideia inicial de cada atividade foram iniciativas dos docentes; em outros, as bolsistas e o coordenador do projeto fizeram tais proposições, sempre respeitada a autonomia docente de cada professor participante. O mesmo ocorreu durante a realização das atividades, isto é, houve aquelas que foram conduzidas pelas bolsistas e coordenador do projeto, houve algumas divididas entre a equipe do projeto e o professor, e, finalmente, outras ministradas pelo docente da escola. Naquela oportunidade, buscamos efetivar, no planejamento de práticas pedagógicas, as ações de educação ambiental em uma abordagem crítica, desestruturando aspectos de tendência conservadora. Essa etapa foi registrada através de observações das ações de EA implementadas pelos professores junto às turmas e com auxílio das bolsistas de extensão universitária.

A última etapa, em termos da metodologia desta pesquisa, consistiu, ao final do ano letivo da escola, em entrevistas semiestruturadas com os professores que desenvolveram atividades nas turmas. A entrevista é um recurso metodológico comumente adotado em pesquisas qualitativas. Segundo Triviños (1987), a entrevista semiestruturada valoriza a presença do investigador, além de oferecer liberdade e espontaneidade necessárias ao entrevistado, enriquecendo a investigação. $\mathrm{O}$ autor ainda afirma que esse tipo de entrevista, em geral, parte de certos questionamentos básicos, apoiados em teorias e hipóteses, que interessam à pesquisa, e que, em seguida, oferecem amplo campo de interrogativas, fruto de novas hipóteses que vão surgindo à medida que se recebe as respostas do informante. 
Sob esse ponto de vista, o caráter semiestruturado do roteiro confere certa flexibilidade para fazer outras perguntas no decorrer da entrevista, e compreender outros aspectos das respostas pelo entrevistado, quando elas forem aparecendo. Optou-se por entrevistar quatro professores que desenvolveram atividades junto com a equipe do projeto para suas turmas. Assim, foi possível analisar, de modo mais aprofundado, as respostas dos mesmos a algumas questões, tais como: (1) Qual sua opinião sobre esse contato entre universidade e escola?; (2) Fazendo um balanço do projeto, quais foram os pontos positivos e o que pode melhorar para o próximo ano?; (3)Você conseguiu identificar a diferença entre as vertentes crítica $e$ conservadora da educação ambiental? Tais questões correspondem, portanto, aos diferentes objetivos desta investigação, quer sejam compreender as concepções dos professores da escola acerca das macrotendências presentes no campo da EA ao final do processo de formação continuada, investigar como os docentes dessa escola pensam a relação entre universidade e escola e analisar perspectivas e limites do trabalho docente no interior da escola junto às ações extensionistas.

\section{Resultados e discussão}

A relação entre universidade e escola pode ser percebida quanto à receptividade, interesse e adesão da comunidade escolar ao projeto de extensão, que transitou desde a direção, passando pela coordenação pedagógica e o conjunto de professores de diferentes disciplinas (sobretudo, de Artes Cênicas, Ciências, Geografia, História, Língua Portuguesa e Língua Inglesa). A maior parte dos docentes demonstrou grande interesse em participar, tendo feito contribuições importantes para a construção das atividades e atuado ativamente no processo de discussão e realização das mesmas.

A proximidade universidade-escola transcorreu mediante o projeto pautado no diálogo e nas ações conjuntas entre os professores e direção da escola e a equipe da universidade, pois corroboramos com Freire (2006), o qual compreende que algo que é transmitido e não produzido pelos participantes, manifesta a superioridade de quem realiza a ação extensionista, desconsiderando a visão de mundo dos que vão participar dela. Nesse sentido, questionamos os professores, principal público-alvo da ação extensionista, acerca de sua opinião sobre o contato escola-universidade, e obtivemos respostas positivas, como a da Coordenadora Pedagógica (CP), que afirmou que as estudantes da universidade e os alunos da escola "começaram a interagir e estabeleceram um diálogo. Muito legal isso!" (CP, 2018, s.p.). Opinião reforçada pelo professor 1 e professora 2:

É! Primeiro [...] acho também que é uma associação muito bacana, muito produtiva [...] a universidade na escola e no ensino fundamental [...] é [...] uma parceria, né, que se estabelece, que é muito produtiva! (Professor 1, 2018, s.p.)

Muito legal! Que foram duas estagiárias, né? Ih... Acho muito legal isso, que as futuras professoras [estagiárias], que estão ainda estudando na universidade possam experimentar um pouquinho do que é a realidade [...]. (Professora 2, 2018, s.p.)

A extensão universitária ampliou a relação entre a universidade e a comunidade escolar, e, segundo Tauchen, Monteiro e Viero (2012), ela vem percorrendo diferentes conotações práticas e concepções ao longo do tempo. A atual concepção sobre o papel da extensão permeia propostas que se distanciam das políticas sociais compensatórias ou assistencialistas, mas que sinaliza para o potencial de projetos como mecanismos de produção e difusão de conhecimento emancipatório (PEREIRA; GOMES, 2018). Apesar dessa concepção emancipatória, ainda há uma lacuna na práxis extensionista. Obstáculo expresso pelo professor 3 (2018, s.p.): "Muito positivo, porque o que nós vemos, na maior parte dos casos, é o distanciamento tanto da escola 
pública, trabalhando no seu mundo particular, como da universidade, teorizando sobre um mundo que não conhece", e reforçado pela professora 4:

[...] A universidade repensa a teoria numa proximidade maior com a realidade da escola, com a realidade das dificuldades, como foi colocado na apresentação final de vocês [...] Para as universitárias [a oportunidade] de ter um contato maior com a escola, numa outra posição que não é mais aluno, e pra gente [...] [pois] o professor [ganha] um apoio da teoria da universidade, com novas ideias [...] (Professora 4, 2018, s.p., grifos nossos).

Logo, percebe-se a importância de troca entre a universidade e escola, mas que não sustenta efetiva integração na perspectiva de fortalecer seu compromisso social, condição oriunda, também, do "distanciamento entre a produção do conhecimento na universidade e o trabalho docente na escola pública" (TEIXEIRA; TALAMONI, 2012, p. 3). Essa troca na relação escola-universidade é reflexo de dois espaços formais de educação, organizados em diferentes contextos, linguagens e finalidades sociais, mas que demandam diálogo entre os saberes acadêmicos e os saberes escolares em um campo mais aberto, desestruturando quaisquer relações unilaterais que possam fragmentar a comunicação reintegradora dos espaços, diminuindo a lacuna na práxis extensionista.

Em seu estado da arte sobre produções acadêmicas que pesquisaram a formação de professores na extensão universitária, Kochhann (2017) elaborou um quadro que sintetiza as perspectivas e limites dessas ações. A autora levantou dezessete limites e 26 perspectivas apontados pelos trabalhos sobre formação de professores na extensão universitária. Dos pontos que ela menciona, identificamos, em nosso projeto, alguns aspectos, como limites: (1) tensionamentos na concepção de extensão; (2) distanciamento entre a teoria e a prática; e (3) fragilidade com a prática docente. E, sobre o panorama relacionado ao projeto de extensão, entendemos ter avançado nas seguintes perspectivas: (1) ações permanentes; (2) favoreceu a reflexão da trajetória formativa; (3) favoreceu a formação acadêmica e humana; (4) potencializou a relação dialógica entre a comunidade escolar e a universidade; (5) possibilitou uma práxis articuladora; (6) potencializou a sólida contextualização, no caso, da EA critica.

Quando questionamos os docentes sobre as diferentes vertentes de EA (conservadora e crítica), depois da vivência com a equipe do projeto, formalmente, em um primeiro momento, eles perceberam a importância de trabalhar a temática da EA na escola; quanto à diferença entre as três macrotendências de EA (conservacionista, pragmática e crítica), percebemos dois grandes grupos de respostas: uma tendência a reconhecer e defender essa diferenciação em prol de uma perspectiva crítica de EA, e outra no sentido de mesclar alguns aspectos das vertentes conservadora e crítica no trabalho com os estudantes da escola. Na fala dos professores 4 e 5 , por exemplo, percebe-se esta segunda tendência:

[...] Eles [alunos] prestaram muita atenção nas informações sobre o uso da água, ficaram muito impressionados com os dados que eles não tinham se atentado sobre o tempo de produção da calça jeans [...]por exemplo; a quantidade de água do planeta [...] Esse momento de se preocupar com a quantidade de água no planeta, e que a gente usa a água sem pensar [...] [torna-se uma oportunidade ao aluno de] passar a pensar nesse uso. Acho que foi um pouco o ganho, que eles [alunos] começaram a entender que não basta só usar sem pensar, que é possível, daqui para a frente] repensar essa utilização do recurso da água, acho que isso foi o mais legal!” (Professora 4, 2018, s.p., grifos nossos).

[...]Essa proposta aí [do projeto em EA Crítica] é boa. Se a gente tiver uma outra proposta também de reeducação do consumo, da gente ter outras maneiras de consumir... e o brechó entra nessa ação, [...] [incentiva] uma mudança de conduta [...] (Professora 5, 2018, s.p., grifo nosso). 
Há dificuldade de alguns docentes da escola em compreender as três macrotendências como concepções distintas, não entendendo o antagonismo entre EA crítica e conservadora, demonstrando um certo ecletismo no entendimento geral das concepções de EA. Em sua fala, a professora 4 relata uma discussão que foi feita com uma turma na qual apresentamos a distribuição desigual do consumo de água pelos diferentes setores (cerca de $70 \%$ na agricultura, $22 \%$ na indústria e $8 \%$ no uso doméstico) e as quantidades de água utilizadas na produção de diferentes mercadorias, sendo 11 mil litros em uma calça jeans (G1 Fantástico, 2015). Tudo isto em um contexto em que denunciávamos o caráter desigual do consumo de água e que as campanhas pela redução do consumo doméstico estão dentro de uma perspectiva conservadora, dentro da macrotendência pragmática de EA. Entretanto, percebemos que apesar do impacto dessas informações, tanto para a turma quanto para a própria professora, por vezes, ainda ocorre uma certa culpabilização genérica dos indivíduos pelo consumo.

Esse debate foi retomado em uma oficina com os professores, e é nesse contexto que a professora 5 se coloca. Essa professora elogia a proposta do projeto de extensão, alicerçado na EA Crítica, de atacar as obsolescências programada e simbólica disseminadas pelas corporações, pautadas no valor de troca e não no valor de uso e na necessidade social das mercadorias, o que tem como consequência o estímulo ao consumo. Entretanto, a professora busca conjugar essa proposta com uma estratégia de cunho pragmático de reutilização de mercadorias, evidenciada com o exemplo dos brechós. É preciso enfatizar, novamente, o caráter desigual que permeia o consumo das mercadorias nas sociedades capitalistas. Nem todos dispõem das mesmas possibilidades para consumir e essa é uma questão central que precisa ser constantemente enfocada. Os próprios brechós, por vezes, tornam-se espaços que atendem a parcelas mais abastadas, é bom lembrar, muito embora haja brechós de caráter mais popular.

Pode-se apontar, como causas desse processo que leva a uma confusão sobre as diferentes perspectivas teóricas e práticas de EA, a carência de materiais didáticos em uma vertente crítica de EA, em contraposição aos materiais que chegam às escolas produzidos por empresas e ONGs em uma abordagem conservadora, e a carência da inserção da EA Crítica na formação de professores, graças à hegemonia da concepção conservadora (seja via macrotendência conservacionista ou pragmática) nos cursos de graduação e pós-graduação.

Contrapondo a percepção de uma EA conservadora, alguns docentes expressaram maior esclarecimento sobre as três macrotendências de EA, como os professores 1 e 6 :

[...] [com] esse projeto, eu acho que [a escola] tem um ganho qualitativo muito interessante, porque ele tira a discussão ambiental só de uma questão ética, né, e passa por uma questão de uma crítica, né?! [...]Porque, hoje em dia, a gente vê a questão ambiental ligada à um discurso muito ético, do que é ético, do que não é ético, do que é de comportamento, do que não é de comportamento, e esse projeto especificamente trouxe a discussão da teoria crítica, de pensar o meio ambiental de [modo] mais totalitário (sic), de forma mais total [...] isso é um ganho fundamental, porque se pensa enquanto sociedade, no coletivo [...] e não assim [...] [de modo] que [...] fica uma coisa que como se cada um tivesse que resolver o problema sozinho, e sozinho não dá para resolver o problema (Professor 1, 2018, s.p., grifos nossos)

[...]Sim, a EA ambiental convencional [...] ela põe muito foco nas ações pessoais, enquanto a crítica mostra pra gente, claro, que o cidadão sempre vai ter uma parcela de responsabilidade, mas não corresponde a totalidade do impacto que é causado das grandes indústrias[...] Essa perspectiva se abre a partir do momento que o trabalho [do projeto] foi apresentado [...] (Professor 6, 2018, s.p., grifos nossos)

O trabalho de extensão na formação continuada dos professores potencializa o diálogo e a discussão sobre a EA crítica, mas não significa que essa vertente será apreendida e mobilizada de modo automático na prática docente. Isto tendo em vista todo processo de formação regulado aos fundamentos teórico-metodológicos pragmáticos, individualistas e 
comportamentalistas, comuns às ações de educação ambiental conservadora, hegemônica nas sociedades capitalistas. Isso demonstra o quanto a extensão é um processo contínuo, que demanda tempo, e não podemos desconsiderar o processo de formação humana, e os diversos fatores políticos, ideológicos e histórico-culturais que o determinam A tomada de consciência da realidade social é um processo complexo, que envolve diversas instâncias e mediações, não podendo ser reduzido ou encurtado, a despeito da vontade de quem está exercendo o papel de formador de um determinado grupo em um dado contexto.

Outra questão é a intensificação e precarização do trabalho docente, que dificulta o processo educativo. Diante das circunstâncias da escola, é necessário que a universidade aprenda com a realidade concreta desse espaço e, principalmente, considerando as condições de trabalho do professor, que ademais pode ser aspecto inibidor dos processos de formação continuada. Segundo Macedo e Lima (2017):

\begin{abstract}
O aumento das funções exercidas pelos docentes no interior das escolas, a distribuição da carga horária que estende o tempo de permanência dos docentes com os estudantes, mas não reserva tempo para estudo, para o planejamento individual e coletivo, para preparação e correção de materiais e, a falta de pessoal administrativo e de suporte pedagógico conjugam-se como aspectos de uma mesma estratégia de intensificação do trabalho docente (MACEDO; LIMA, 2017).
\end{abstract}

A precarização do trabalho docente atravessado pelo viés da ampliação e intensificação das funções docentes, acarreta na falta de tempo do mesmo para refletir sobre seu próprio trabalho, assim estabelecendo um certo padrão de atuação que pressupõe uma menor autonomia docente. Esta questão dificulta uma possível participação em projetos de extensão com formação continuada de professores, pois há uma apreensão dos docentes em relação ao aumento de suas responsabilidades escolares, situação explicitada pela professora 7:

[...] No início eu achei que o professor teria que ir fazendo as atividades, e não que vocês iriam fazer. Aí eu não quis participar porque achei que eu deveria desenvolver um projeto com eles [alunos] além do trabalho que eu já tinha que fazer. (Professora 7, 2018, s.p., grifos nossos).

É relevante considerar, a partir da fala da professora 7, que o sentimento de recusa gerado, a princípio, em relação à inserção e execução do projeto de extensão universitário, é o reflexo contínuo da precarização do trabalho docente mediante o acúmulo de tarefas disfarçado no discurso do "melhor desempenho, eficiência e produtividade". Segundo Lukács (2013 apud ALVES, 2013, p. 86), a precarização do trabalho contemporâneo, sob o modelo do sistema capitalista, seria não apenas precarização do trabalho no sentido da mera força-de-trabalho como mercadoria; mas, também, "precarização do homem-que-trabalha". Dessa forma, importante caracterizar a intensificação da exploração do trabalho docente por meio da captura da subjetividade de quem trabalha.

Essa fala da professora 7 corrobora com Dal Rosso $(2008$, p. 23) em relação à lógica produtivista mediante a intensificação do trabalho:

Os processos de quaisquer naturezas que resultam em maior dispêndio das capacidades físicas, cognitivas e emotivas do trabalhador com o objetivo de elevar quantitativamente ou melhorar qualitativamente os resultados. Em síntese, mais trabalho.

Desse modo, a condição de submersão do trabalho docente no interior da escola vai, autonomamente, alienando o processo de trabalho e colaborando com a desprofissionalização docente (MACEDO; LIMA, 2017). Ações de extensão em uma perspectiva emancipatória, mesmo exigindo dispêndio de tempo de trabalho dos professores, são antagônicas à 
intensificação alienante do trabalho docente, já que proporcionam a eles subsídios teóricometodológicos, visando a produção de materiais e atividades, de modo a possibilitar um fortalecimento da autonomia docente para a elaboração de práticas de educação ambiental na perspectiva crítica.

Entretanto, diante da intensificação do trabalho docente, não se está livre do risco de os professores reduzirem o papel da extensão a uma concepção salvacionista, atribuindo função compensatória (um suporte pedagógico) às atividades do projeto devido à sobrecarga de trabalho. Notório na fala do professor 1, quando questionado sobre a possibilidade de continuidade do projeto de extensão: "Foi muito produtivo [...] espero que continue, aprovado! Espero que seja renovado! Que nunca acabe essa associação! [...]” (Professor 1, 2018, s.p., grifo nosso). Ao mesmo tempo que conta os ganhos com a inserção da universidade na escola, há um sentimento de permanência e dependência do projeto, pois a presença dos acadêmicos auxilia, na prática, as ações pedagógicas, assim compensando parcela da demanda escolar.

Portanto, faz-se necessário fortalecer a extensão universitária capaz de contribuir com a emancipação humana. Nesse sentido, o projeto assume posição contrária à noção salvacionista da extensão, realizando um trabalho em conjunto com a comunidade escolar. Quanto à avaliação do projeto pelos professores, houve um retorno positivo da grande maioria dos docentes. Os pontos negativos relatados pelo corpo docente permitem uma reavaliação das atividades aplicadas, assim possibilitando a superação de alguns dos limites que interferem na inserção e permanência da educação ambiental crítica: a dinâmica da escola, os prazos, os quais podem impossibilitar um trabalho contínuo e permanente, lidar com o desinteresse dos alunos e com a dificuldade de trabalhar com as turmas.

Constatou-se, dessa forma, que as ações esclareceram e distinguiram a EA Crítica da EA Conservadora em parte do grupo docente, e mesmo o grupo que não percebeu as distinções de EA conseguiu perceber a importância do projeto de extensão e os resultados positivos das atividades, pois o projeto não se limitou ao campo teórico, e desenvolveu a discussão do assunto durante a prática, facilitando a materialização da EA Crítica nas ações pedagógicas. Dentro desse pressuposto, a formação continuada com docentes organiza-se e desenvolve-se dentro da proposta de ação extensionista fundada na compreensão do trabalho docente, dos fundamentos teóricos e metodológicos da EA crítica e da elaboração de novas estratégias pedagógicas.

\section{Conclusão}

Este trabalho buscou compreender as concepções dos professores de uma escola pública municipal acerca das macrotendências presentes no campo da EA ao final do processo de formação continuada, investigar como esses sujeitos pensam a relação entre universidade e escola e analisar perspectivas e limites do trabalho docente no interior da escola junto às ações extensionistas, em um projeto de extensão universitária em Educação Ambiental Crítica, sob o aporte da Pedagogia Histórico-Crítica (PHC).

Como instrumentos de análise foram realizadas entrevistas semiestruturadas, colhidos registros orais e observações em quatro oficinas de formação com os professores da escola. A aproximação entre universidade e escola se efetivou de maneira bastante produtiva para ambas, fortalecendo essa parceria. Com a disposição da comunidade escolar de abrir espaço para a formação continuada de professores em educação ambiental crítica, levantaram-se novas reflexões e debates entre professores, expandindo seus repertórios de conhecimento e suas possibilidades de trabalho com os alunos. A prática na escola também contribuiu na formação inicial docente das bolsistas do projeto, tanto no aspecto do planejamento e realização de atividades de EA em um viés crítico-transformador, quanto no contato com professores de diversas turmas e áreas do conhecimento. 
As atividades realizadas nas aulas, até então, têm tido uma boa receptividade por parte do corpo docente, mostrando que a interação com a universidade tem despertado, principalmente nos professores, bons resultados dentro do espaço formativo, influenciando positivamente, de forma direta, a participação dos alunos e da direção escolar.

Diante dos resultados da pesquisa de Kochhann (2017, p. 289), estamos de acordo com as categorias indicadas pela autora como possibilidades para a formação de professores no espaço da extensão universitária, quais sejam: (i) a extensão é componente curricular; (ii) promove a unidade teoria e prática; (iii) fomenta a produção do conhecimento científico; (iv) favorece a formação política e emancipadora; (v) a temporalidade das ações de extensão serem permanentes; (vi) a assumência das instâncias competentes; (vii) a efetivação do tripé universitário. Ainda que haja desafios relacionados em parte pela precarização do trabalho docente, é possível, por meio da extensão universitária, desenvolver aspectos que possam caracterizar-se como resistência e enfrentamento a um sistema educacional que inibe o viés emancipatório. Nesse sentido, a formação inicial e continuada de professores em educação ambiental crítica, no âmbito da extensão universitária, nos parece ser parte importante de uma estratégia mais ampla para caminharmos em direção a uma formação humana de caráter emancipatório.

\section{Referências}

ALVES, G. Dimensões da precarização do trabalho: ensaios de sociologia do trabalho. Bauru: Canal $6,2013$.

BRASIL. MEC/INEP. O que fazem as escolas que dizem que fazem Educação Ambiental? Coleção Educação para todos. Brasília: Edições MEC/UNESCO, 2007. Disponível em: portal.mec.gov.br/dmdocuments/publicacao5.pdf. Acesso em: 22 dez. 2021

COSTA, G. C.; LIMA, M. J. G. S. Educação Ambiental na escola: uma análise das concepções e práticas presentes em relatos de experiência dos Encontros Regionais de Ensino de Biologia RJ/ES. In: ENCONTRO PESQUISA EM EDUCAÇÃO AMBIENTAL, 8, 2015, Rio de Janeiro. Anais do VIII Encontro Pesquisa em Educação Ambiental (EPEA), Rio de Janeiro: Unirio e UFRJ, 2015. p. 1-15. Disponível em: http://epea.tmp.br/epea2015_anais/pdfs/plenary/86.pdf. Acesso em: 8 jun. 2020.

DAL ROSSO, S. Mais Trabalho!: A intensificação do labor na sociedade contemporânea. São Paulo: Boitempo, 2008.

FABRICAÇÃO de uma calça jeans consome 11 mil litros de água. Gl Fantástico, Rio de janeiro, 18 de fevereiro de 2015. Disponível em: http://g1.globo.com/fantastico/noticia/2015/02/fabricacao-de-umacalca-jeans-consome-11-mil-litros-de-agua.html. Acesso em: 18 mai. 2021.

FIGUEIRA, M. R.; SOARES, A. G.; BASTOS, C. B.; COSTA, G. C.; ASSUMPÇÃO, T. L.; LIMA, M. J. G. S. Educação Ambiental, consumo e alimentação: uma temática para o ensino de ciências. In: VII Encontro Regional de Ensino de Biologia - Regional 2, 2015, Niterói - RJ. Anais do VII EREBIO RJ/ES - VII Encontro Regional de Ensino de Biologia RJ/ES: tecendo laços docentes entre Ciência e culturas. Niterói, Rio de Janeiro: MGSC Editora, 2015. p. 479-483. Disponível em: http://www.sbenbio.org.br/wordpress/wpcontent/uploads/2015/12/VII_EREBIO_Anais_Final_14_12. pdf Acesso em: 17 ago. 2018.

FREIRE, P. Extensão ou comunicação? 13 ed. Rio de Janeiro: Paz e Terra, 2006.

KOCHHANN, A. Formação de professores na extensão universitária: uma análise das perspectivas e limites. Teias, Rio de Janeiro, v. 18, n. 51, p. 276-292, 2017. 
LAMOSA, R. A. C. A educação ambiental e o novo padrão de sociabilidade do capital: um estudo nas escolas de Teresópolis (RJ). 2010. 168 fls. Dissertação (Mestrado em Educação) - Universidade Federal do Rio de Janeiro, Rio de Janeiro, 2010.

LAMOSA, R. A. C.; LOUREIRO, C. F. B. A educação ambiental e as políticas educacionais: um estudo nas escolas públicas de Teresópolis (RJ). Educ. Pesquisa, São Paulo, v.37, n.2, p. 279-292, 2011.

LAYRARGUES, P. P.; LIMA, G. F. C. As macrotendências político-pedagógicas da educação ambiental brasileira. Ambiente \& Sociedade, São Paulo, v. 17, n. 1, p. 23-40, jan.-mar. 2014.

LIMA, M. J. G. S. O que fazem as escolas que fazem educação ambiental no rio de janeiro? Uma análise da pesquisa realizada pelo MEC/UFRJ/Anped à luz da teorização curricular. In: 30a Reunião da Anped: anped: 30 anos de pesquisa e compromisso social, 2007, Caxambu - MG. Anais da 30a Reunião Anual da Anped, 2007. p. 1-18. Disponível em: https://www.anped.org.br/biblioteca/item/o-que-fazemescolas-que-fazem-educacao-ambiental-no-rio-de-janeiro-uma-analise-da

Acesso em 21 de junho de 2020.

LOUREIRO, C. F. B.; COSSÍO, M. F. B. Um olhar sobre a educação ambiental nas escolas: considerações iniciais sobre os resultados do projeto "O que fazem as escolas que dizem que fazem educação ambiental". In: MELLO, S.; TRAJBER, R. (Orgs.) Vamos cuidar do Brasil: conceitos e práticas em educação ambiental. Brasília: MEC/UNESCO, 2007. P. 57-64

LOUREIRO, C. F. B. Premissas teóricas para uma educação ambiental transformadora. Ambiente \& Educação, Rio Grande, v. 8, n. 1, p. 37-54, 2003.

LUKÁCS, G. Para uma ontologia do ser social II. São Paulo: Boitempo, 2013.

MACEDO, Jussara Marques de ; LIMA, Miriam Morelli. Fundamentos teóricos e metodológicos da precarização do trabalho docente. Revista trabalho, política e sociedade , v. 2, p. 219-242, 2017.

MACEDO, J.; MELLO, M. Fundamentos teóricos e metodológicos da precarização do trabalho docente. RTPS - Revista Trabalho, Política e Sociedade, Seropédica, v. 2, n. 3, p. 219-242, dez. 2017.

MACEDO, J. M. Formação para o trabalho docente. Curitiba: Appris, 2017.

MAIA, J. S.; TEIXEIRA, L. A. Formação de professores e educação ambiental na escola pública: contribuições da pedagogia histórico-crítica. Revista HISTEDBR On-line, Campinas, s.v., n. 63, p. 293305, jun. 2015.

MAIA, J. S.; TEIXEIRA, L. AGUDO, M. M. Educação ambiental como campo de disputas: a necessária discussão epistemológica. Planeta Amazônia: Revista Internacional de Direito Ambiental e Políticas Públicas, Macapá, s.v., n. 7, p. 75-87. 2015.

MARX, K. O método da economia política. Contribuição à crítica da economia política. São Paulo: Expressão Popular, 2008.

PEREIRA, T. I.; GOMES, T. F. A extensão universitária em debate: o curso pré-universitário como espaço de educação popular. Revista Espaço Pedagógico, Passo Fundo, v. 25, n. 3, p. 665-684, ago. 2018.

RODRIGUES, G. S.; PINTO, B. C. T.; FONSECA, L. C. S.; MIRANDA, C. C. O estado da arte das práticas didático-pedagógicas em educação ambiental (período de 2010 a 2017) na Revista Brasileira de Educação Ambiental. Revista Brasileira de Educação Ambiental (RevBEA), São Paulo, v. 14, n. 1, p. 09-28, 2019. 
SAVIANI, D. Escola e democracia. Ed. Comemorativa. Campinas: Autores Associados, 2008.

SEVERINO, A. J. Modalidade e metodologias de pesquisa científica. In: SEVERINO, Antonio Joaquim. Metodologia do trabalho cientifico. 24. ed. São Paulo: Cortez, 2016.

TAUCHEN, G.; MONTEIRO, M. C. M.; VIERO, T. V. Políticas, concepções e ações de extensão na educação superior brasileira. Momento - Diálogos em Educação, [S. l.], v. 21, n. 1, p. 09-28, 2013.

TEIXEIRA, L. A.; TALAMONI, J. L. B. A relação teoria e prática e a educação ambiental na escola: pensando a formação docente na perspectiva da pedagogia histórico-crítica. In: XVI ENCONTRO NACIONAL DE DIDÁTICA E ENSINO, 16, 2012, Campinas. Anais do XVI ENDIPE - Didática e práticas de ensino na realidade escolar contemporânea: constatações, análises e proposições. Tommasielo, M. G. C. et al (Orgs.). Campinas: Universidade Estadual de Campinas, 2012. p. 1-12. Araraquara, SP: Junqueira \& Marin, 2012 [recurso digital]

TOZONI-REIS, M. F. C. Contribuição para uma pedagogia crítica na educação ambiental: reflexões teóricas. In: LOUREIRO, Carlos Frederico Bernardo; TREIN, Eunice; Pedrosa, José Geraldo; TOZONIREIS, Marília Freitas de Campos; LEHER, Roberto; NOVICKI, Victor. A questão ambiental no pensamento crítico: natureza, trabalho e educação. Rio de Janeiro: Quartet, 2007. p. 177-221

TRAJBER, R.; MENDONÇA, P. R. (Orgs.). O que fazem as escolas que dizem que fazem Educação Ambiental? Brasília: Edições MEC/UNESCO, 2006. (Coleção Educação para todos).

TRIVIÑOS, A. N. S. Introdução à pesquisa em ciências sociais: a pesquisa qualitativa em educação. São Paulo: Atlas, 1987. 